\title{
Improving the Cultural and Historical Tourism Resources for Sustainable Development in Ondo State - A Survey of Idanre Hills and Resort Centre, Idanre
}

\author{
Ikusemiju T. M. ${ }^{1, *}$ and Osinubi O. B. ${ }^{2}$ \\ ${ }^{1,2}$ Department of Hospitality, Leisure and Tourism Management, School of Applied Sciences, Federal \\ Polytechnic Ede, Osun State, Nigeria \\ Corresponding Author: *toluwalase20002000@gmail.com
}

https://doi.org/10.36263/nijest.2020.01.0182

\begin{abstract}
It has been observed that necessary attention has not been given to Idanre hills and resort centre as tourists' attraction and its sustainability is being threatened. Thus, this paper revealed that many studies have been carried out on Idanre hills and resort centre but had only focused on its beautifications, geo - tourism potentials, landscape management, maintenance and tourists' patronage pattern. Hence, the objectives of this study revealed possible strategies of making the cultural and historical tourism attraction of Idanre hills and resort centre sustainable for both this generation and the future generation and how these strategies can specifically be of economic and social benefits to the residents of Idanre community for sustainable livelihood. The study adopted oral interview, personal observation and administration of questionnaire for data collection of which 200 questionnaires were administered and 188 were returned representing $94.00 \%$. Meanwhile, the questionnaires were presented and analyzed with the use of simple percentage method while percentage point of $t$ - test distribution (One - tailed) analysis was adopted in validation of the hypothesis. The result indicated that $t$ (calculated) was 0.13 and was greater than $t$ (tabulated) of -2.92; thus, the null hypothesis was rejected, while the alternative hypothesis was accepted, which states that there are promising economic and social benefits of specifically developing and sustaining the cultural and historical tourism resources of Idanre hills and resort centre. The study concluded that if Ondo State Government and relevant tourism stakeholders should put the necessary strategies in making the cultural and historical tourism resources of Idanre hills and resort a haven in place; its development will have specific economic and social benefits such as economic stability and social integration etc. on the residents of Idanre community and Ondo State at large by stimulating its local economy both directly and indirectly through multiplier effects.
\end{abstract}

Keywords: Cultural, Historical, Economy, Social, Sustainable development and Tourism Resources

\subsection{Introduction}

Tourism comprises the multidimensional activities of people travelling to and staying in places outside their usual place of residence for a specified period of twenty four hours and not more than one consecutive year for leisure, business, sightseeing and other purposes not related to activity remunerated from within the place visited. The activities spread across economic, social, cultural and environmental nature of many lives and communities (Sudhir, 2007).

The tourism industry is one of the world's largest industries with a world trade contribution (direct, indirect and induced) of over 7.6 trillion U.S. dollars in 2016 ranged in terms of accommodation, transportation, entertainment etc. of which 2.3 trillion U.S dollars came as a result of direct contribution to the economy. A number of countries such as France, Egypt and the United States of America are consistent popular tourism destinations but other, less well-known countries as Nigeria are quickly emerging in order to reap the economic benefits of the tourism industry. Thus, the tourism industry globally has continued to experience steady growth almost every year with international 
tourist arrivals increased from 528 million in 2005 to 1.19 billion in 2015 with global international tourism revenue reaching approximately 1.26 trillion U.S. dollars, having almost doubled since 2005 . Figures were forecasted to exceed 1.8 billion by 2030 (Makoondlall-Chadee et al., 2017).

Cultural and historical resource has always been a major objective of travel as the development of the tourism industry from the 16th century till date attest to the fact that cultural and historical attractions of the industry play an important role in tourism at all levels from the global highlights of world culture to attractions that strengthen local identities. Also, in recent years cultural and historical resources has been rediscovered as an important marketing tool to attract those travellers with special interests in heritage and arts (Richard, 2016). Similarly, Jin (2002) quoting Hollinshed (1993) stated that cultural and historical tourism is the fastest growing segment of the tourism industry because there is a trend toward an increase specialization among tourists.

Cultural and Historical tourism also known as heritage tourism or diaspora tourism is a derivative of tourism industry geared towards the cultural and historical heritage of a locality. Thus, The National Trust for Historic Preservation describe heritage tourism as traveling to experience historical places, places of artifacts and activities that authentically represent the stories and people (Wall and Mathieson, 2016).

Accordingly, cultural and historical tourism is important as it has positive economic and social impacts, it establishes and reinforces identity, it preserve the cultural and historical heritage with culture and histories as instrument to facilitate harmony and understanding among the people (Suleiman, 2010).

The trend aforementioned have been observed as the number of tourists / visitors who seek adventure, culture, history and interaction with local people of Idanre is increasing on regular and daily base.

Hence, for sustainable development of Ondo State; Idanre hills in the context of cultural and historical tourism resources has a number of objectives which include the conservation of cultural and historical attractions, accurate interpretation of cultural attractions, value for money / visitors experience. The utilization of the earned revenues of cultural and historical resources for economic and social benefits of the community and the nation as whole must be met within the perspective of United Nations Sustainable Development Goals (SDGs) and these are decent work and economic growth (Goal number 8), Industrial Innovation and Infrastructure (Goal number 9), Sustainable cities and communities (Goal number 11) and Partnership for the goals (Goal number 11) (Rieder, 2012).

In Nigeria, tourism industry and its derivatives has the capability of huge relief of providing employment, revenue, social cohesion among others if necessary attention of sustainable tourism practices is given. Thus, for economy wellbeing of the host community (Goal 8), Idanre hills has the capability of generating a lot of direct revenue into treasury of Ondo State government.

The study is imperative for the reason that many different cultural and historical tourism resources in different places such as Idanre hills and resort centre have not been given adequate attention and advancement by the government even as many have been ignored, threatened or gone into extinction as a result of lack of commitment by the government. Also, persistence political instability and change of government, inadequate infrastructural facilities do have negative impacts on the cultural resources.

It has been observed that numerous studies such as (Anifowose and Kolawole, 2014) and (Nwanne, 2017) have been carried out on Idanre hills and resort centre but these studies only focused on its beautifications. Also, Ogunbodede (2012) only focused on the pattern of patronage of tourists to Idanre hills and its importance to future generations. Likewise, Adebayo (2019) basically focused on how issues of sustainability are being conceptualized by tourism officials that are responsible for managing Idanre hills and resort centre and how such ideas are incorporated into tourism development. Similarly, Aremu and Lawal (2018) simply focused on the influence of tourism on the sustainable economic development of Idanre residents. Also, Adeniyi et al. (2018) basically focused on the importance of maintaining the infrastructural facilities and monuments on Idanre hills and resort centre. 
Thus, all the aforementioned did not focus on strategies of making the cultural and historical tourism resources of Idanre hills and resort centre a haven and how these strategies can specifically be of economic and social benefits to the residents of the study area. Consequently, this study tends to reveal possible strategies of making the cultural and historical Tourism attractions such as Idanre hills and resort centre to be sustainable for both this generation and the future generation and to disclose how these strategies can specifically be of economic and social benefits to the residents of Idanre community for sustainable livelihood.

The null hypothesis of the study states that there are no promising economic and social benefits of specifically developing and sustaining the cultural and historical tourism resource of Idanre hills and resort centre while the alternative hypothesis states that there are promising economic and social benefits of specifically developing and sustaining the cultural and historical tourism resource of Idanre hills and resort centre.

\subsection{Methodology}

\subsection{Study area}

The Idanre Hill is one of the most beautiful natural landscapes in Ondo State. It consists of high plain with spectacular valleys interspersed with iceberg of about 3,000 ft above sea level and houses a unique ecosystem upon which the cultural landscape has integrated. It is located in Idanre town of land area $1,914 \mathrm{~km}^{2}(739 \mathrm{sq} \mathrm{mi})$ and on the coordinates $7^{\circ} 05^{\prime} 32^{\prime \prime} \mathrm{N}$ and $5^{\circ} 07^{\prime} 56^{\prime \prime} \mathrm{E}$ with a population of 129,024 based on the 2006 population census (Adisa, 2019).

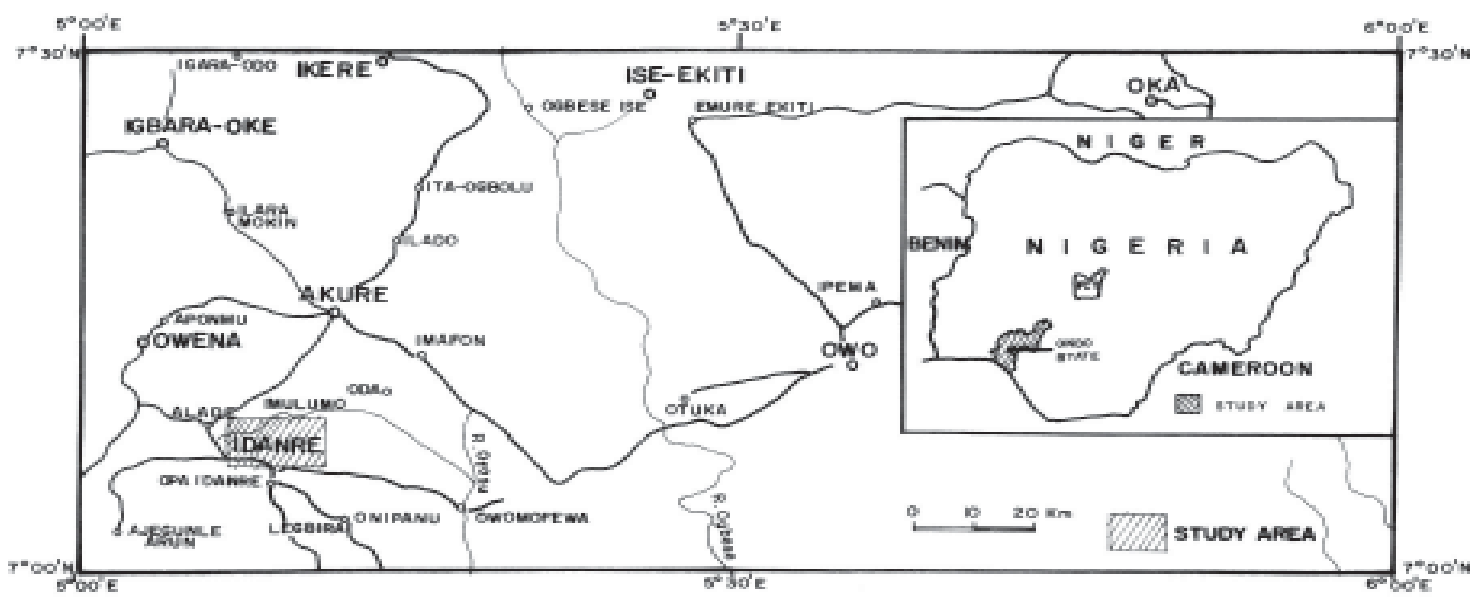

Figure 1: Map of the location of the study area

\subsection{Methods}

The population of the study was a survey of Indigenes / Residents of Idanre, Staff and Tourists at the Idanre hills and resort. The researchers utilized stratified sampling method in the selection of two hundred (200) respondents that encompassed 100 indigenes / residents, 10 staff and 90 tourists. The data gathered through the administration of 200 questionnaires of which only one hundred and eighty eight (188) were returned representing $94.00 \%$ were presented and analyzed with the use of simple percentage method. Meanwhile, the study used Percentage point of T - test distribution (One tailed) in the validation of hypothesis because the standard deviation of the population is unknown (Srivastava, 2019) which assisted the study in a logical conclusion.

However, the sample size of the study was determined by using the Yamane Taro model (Grupta and Kapoor, 2014) based on National Population Commission, 2006 Census in Ondo State.

Sample size $(n)=\frac{N}{1+N(e)^{2}}$

where:

N Population of the study 
e $\quad$ Sampling error $(5 \%)$

Sample size $(n)=\frac{129024}{1+129024(0.05)^{2}}=200$

\subsection{Results and Discussion}

\subsection{Making the Cultural and Historical Tourism Resources}

Table 1 reveals that 180 of respondents representing $90.00 \%$ agreed that of the strategies to upholding the cultural and historical tourism resources of Idanre hills is provision of promotional materials such as souvenirs that will contain the designed and known brand name. Also, 179 respondents representing $89.50 \%$ agreed that one of the ways to enhance Idanre hills as a cultural and historical tourism resource is to maximize fully; the different seasons of the year. Thus, 184 respondents representing $92.00 \%$ believed in uncompromised marketing and publicity while 172 respondents representing $86.00 \%$ agreed that powerful media coverage will greatly enhance the promotion of Idanre hills. Nevertheless, 181 respondents representing $90.50 \%$ were of the opinion of aggressive public, private and community partnership and 187 respondents representing $93.50 \%$ agreed that dependable infrastructural development would be of great support.

Table 1: Strategies of making the cultural and historical tourism resources of Idanre Hills and resort centre a haven

\begin{tabular}{lll}
\hline Variables & Frequency (Agreed) & Percentage (\%) \\
\hline Provision of Promotional material & 180 & 90.00 \\
Maximizing the different seasons of the year & 179 & 89.50 \\
Uncompromised marketing and publicity & 184 & 92.00 \\
Powerful media coverage & 172 & 86.00 \\
Aggressive Public, Private and community partnership & 181 & 90.50 \\
Dependable infrastructural development & 187 & 93.50 \\
\hline Source: Fieldwork (2019) &
\end{tabular}

In discussion, the strategies stated above hold that good cultural and historical conservation strategies require a better appreciation of the heritage asset and integration of such strategies within the larger process of planning and development of urban areas and these include infrastructural/service provision, community participation and urban identity (Srinivas, 2015).

Also, the above is in line with Fadipe (2007); that advocated that strategies to achieve a preferred tourist destination (sustainable development) include the following among others:

1. Concession on existing tourist attractions and provision of infrastructural facilities.

2. Encouraging private sector involvement in tourism and launching awareness campaign within and outside Nigeria.

\subsection{Economic and Social Benefits of enhancing Idanre Hills as a Resort Centre}

Table 2 shows that 178 respondents representing 94.60\% agreed that improving the cultural and historical tourism resources of Idanre hills will add to the economic development of the destination and its stability. Similarly, 184 respondents respecting $98.00 \%$ were of the opinion that cultural and historical tourism resources will help improve physical infrastructure and social integration and strengthen the community identity. Thus, 169 respondents representing $90.00 \%$ believed that its improvement would enhance understanding of environmental and ethic conservation while 185 respondents representing $98.40 \%$ established that its development will stimulate thought of personal responsibility using cultural resources for improved quality of life.

Table 2: The Economic and Social Benefits of enhancing Idanre Hills as a Resort Centre

\begin{tabular}{lll}
\hline Variables & Frequency (Agreed) & Percentage \\
\hline Adds to economic development and stability & 178 & 94.60 \\
Improves physical infrastructural and social integration & 184 & 98.00 \\
Enhances and strengthen community identity & 184 & 98.00 \\
Enhances understanding of environmental and ethic conservation & 169 & 90.00 \\
Stimulate thought of personal responsibility using cultural and historical & 185 & 98.40 \\
tourism resources for improved quality of life. & &
\end{tabular}


The above findings is supported by Dumcke and Gnedovsky (2013) that state that cultural and historical tourism resource of Idanre Hills and Resort centre if properly managed can be instrumental in enhancing social inclusion, improving quality of the environment, creating jobs and enhancing investment climate.

\subsection{Validation of hypothesis}

Using the Table 3 below to test the hypothesis, let $p=$ probability that there are promising economic and social benefits of specifically developing and sustaining the cultural and historical tourism resources of Idanre hills and resort centre to the development of Ondo State.

Table 3: Developing Idanre hills and resort centre will help stimulate the local economy.

\begin{tabular}{lll}
\hline Opinion & Frequency & Percentage $(\boldsymbol{\%})$ \\
\hline Agreed & 166 & 88.00 \\
Disagreed & 16 & 9.00 \\
No Response & 6 & 3.00 \\
Total & $\mathbf{1 8 8}$ & $\mathbf{1 0 0}$ \\
\hline Source: Fieldwork (2019) & &
\end{tabular}

Source: Fieldwork (2019)

Therefore, the sample size $(n)=188$ and degree of freedom (that is, number of columns minus $1 ; 3$ $1)$ is 2 and level of significance is 0.05 .

Thus, $H_{0}: \mathrm{p}=0.88$ (meaning that the population affirmation has not changed)

$\mathrm{H}_{1}: \mathrm{p} \neq 0.88$ (meaning that the population affirmation has changed)

$T_{c}=\frac{x-n p}{\sqrt{n p(1-p)}}$

$T_{c}=\frac{166-188(0.88)}{\sqrt{188(0.88)(1-0.88)}}$

$T_{c}=\frac{0.56}{\sqrt{19.85}}$

$T_{c}=\frac{0.56}{4.46}$

$T_{c}=0.13$

Decision Rule: Reject $H_{o}$ if $T_{c}$ is less than -2.92 ( $\mathrm{T}$ - tabulated) and thus, accept $H_{l}$ if $T_{c}$ greater than 2.92 (see Figure 2).

Decision: Since $T_{c}$ is 0.13 and is greater than -2.92 , therefore, the researchers reject $H_{o}$ and thus, accept $H_{1}$. That is, there are promising economic and social benefits of specifically developing and sustaining the cultural and historical tourism resources of Idanre hills and resort centre to the development of Ondo State. 


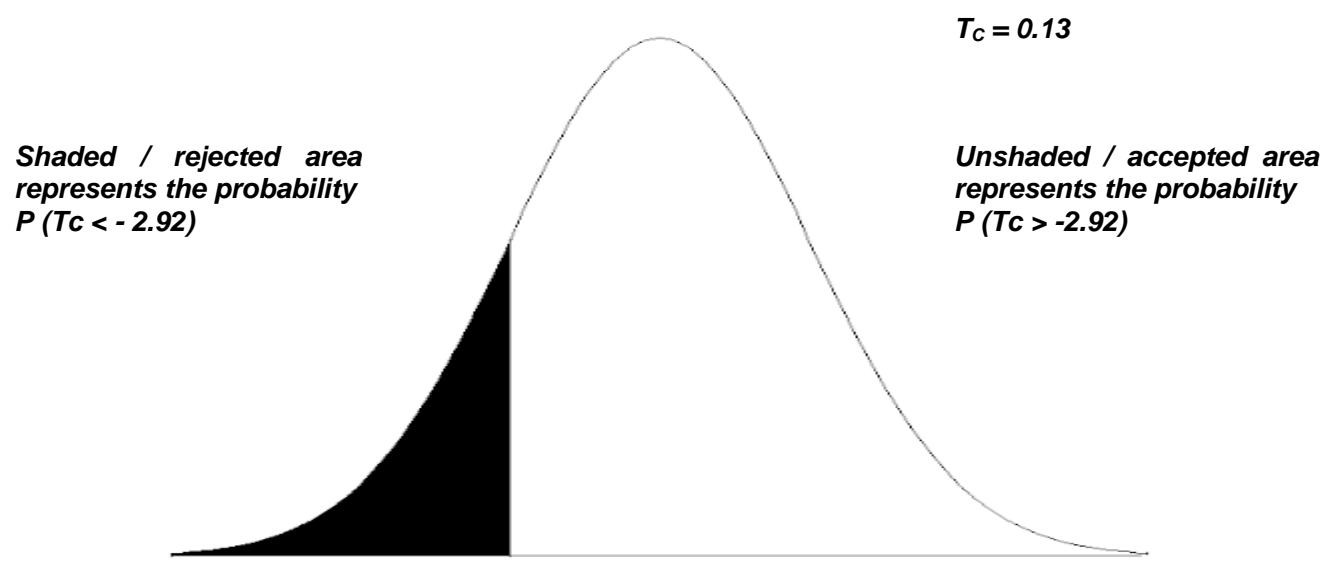

Figure 2: Percentage point of $\mathrm{T}$ - test distribution (one tailed) showing the acceptance area

\subsection{Summary of findings}

From the study, it was discovered that the rational responses of the residents, staff and tourists about Idanre hills and resort centre showed clearly their level of understanding that if cultural and historical tourism resources of Idanre hills and resort centre is properly harnessed, it will be of great economic and social benefits to individuals and the government of Ondo State.

\subsection{Conclusions}

Tourism industry and its derivatives is an inevitable sector that must be sustainable development activated to help stimulate the economic and social wellbeing of the society. The Idanre hills and resort centre have come of age and of which necessary attention and advancement have not being given by the Ondo State government towards its development.

Thus, study concluded that if Ondo State government and relevant tourism stakeholders should put the necessary strategies in making the cultural and historical tourism resources of Idanre hills and resort a haven in place; its development will have specific economic and social benefits such as economic stability and social integration etc on the residents of Idanre community and Ondo State at large by stimulating its local economy both directly and indirectly through multiplier effects.

Based on the study, the researchers recommended the following:

- Strategies for making cultural and historical tourism resources of Idanre hills and resort centre should be encouraged and implemented by Ondo State Government in partnership with relevant tourism stakeholders.

- Basic infrastructural facilities should be provided by the Ondo State Government to enhance sustainable development of Idanre hills and resort centre.

- The strategies required in harnessing the cultural and historical tourism resource of Idanre hills for sustainable development should be integrated with adequate planning, control and development.

\section{References}

Adebayo, A. (2019). Sustainable Tourism in Idanre hill, Nigeria Sustainable Tourism and Cultural Landscape Management: The Case of Idanre hill, Ondo State, Nigeria. Tourism Today, 2016 / 2017 issue, pp. $43-54$.

Adeniyi, J. O., Olugbamila, O. B. and Olajide, T. P. (2018). Assessment of Tourism Potentials and their contributions to the Socio - Economic Development of Idanre People, Ondo State, Nigeria. World Journal of Research and Review, 6(4), pp. 52 - 59. 
Adisa, A. (2019). Idanre Hill - Oke Idanre Ondo State [Online] Come to Nigeria. Available at https://www.cometonigeria.com/top-destination/idanre-hill [Accessed 5 July, 2019].

Anifowose, A. Y. B. and Kolawole, F. (2014). Appraisal of the Geo-tourism Potentials of the Idanre Hills, Nigeria. Journal of European Association for Conservation of the Geological Heritage, 9(6), pp. $193-203$.

Aremu, A. B. and Lawal, L. O. (2018). Tourism Development and Sustainable Economic Development: Evidence from South Western Nigeria. South Asian Journal of Social Studies and Economics, 2(1), pp. $1-9$.

Dumcke, C. and Gnedovsky, M. (2013). The Social and Economic Value of Cultural Heritage: Literature Review [Online] European Expert Network on Culture. Available at https://www.semanticscholar.org [Accessed 23 January, 2018].

Fadipe, A. S. (2007). Basic Principles and Practice of Tourism, Media Ace, Ikeja.

Grupta, S. C. and Kapoor, V. K. (2014). Fundamentals of Applied of Statistics. Sultan Chand, New Delhi.

Jin, H. (2002). Tourist satisfaction with Cultural Heritage Sites [Online] The Virginia Historic Triangle. Available at https://www.hdl.net. [Accessed 9 August, 2018].

Makoondlall-Chadee, T., Bokhoree, C. and Sumputh, D. (2017). A System Thinking Approach towards promoting Sustainability in Tourism Industry. University of Technology, Mauritius.

Nwanne, C. (2017). Destination: Idanre hills [Online] Travel and Tourism. Available at htps://www.m.guardan.ng/Saturday-magazine/travel-a-tourism [Accessed 23 January, 2018].

Ogunbodede, E. F. (2012). Patronage pattern of tourists to Idanre hills and its implication for Tourism Development in Nigeria. Journal of Environmental Research and development, 6(3A), pp. 908 - 915.

Richard, G. (2016). Production and consumption of European Cultural Tourism. Tilburg University, Tilburg.

Rieder, L. (2012). Strategic Tourism Planning and Sustainable Destinations and Sites, UNWTO, Bhutan.

Srinivas, H. (2015). Heritage and Conservation Strategies: Understanding the Justification and Implications [Online] Urban Heritage and Conservation. Available at https://www.gdrc.org/heritage/heritage-strategies.html [Accessed 10 August, 2018].

Srivastava, A. (2019). Types of Statistical Tests [Online] Statistical Test and Assumptions. Available at https://www.medium.com/anushka [Accessed 31 June, 2019].

Sudhir, J. (2007). The Management of Tourism, Wottogs Publication, New Delhi.

Suleiman, A. G. (2010). Understanding Recreation, Leisure and Tourism Practices in Nigeria, Ahmadu Bello University Press, Zaria.

Wall, G. and Mathieson, A. (2016). Tourism: Change, Impacts and Opportunities. Pearson Educational, England.

\section{Cite this article as:}

Ikusemiju T. M. and Osinubi O. B., 2020. Improving the cultural and historical tourism resources for sustainable development in Ondo State - A survey of Idanre Hills and resort centre, Idanre. Nigerian Journal of Environmental Sciences and Technology, 4(1), pp. 197-203. https://doi.org/10.36263/nijest.2020.01.0182 